\title{
Well-Being and Perceived Stress of Adolescent Young Carers: A Cross-Sectional Comparative Study
}

\author{
Hannah Wepf $\mathbb{D}^{1,2} \cdot$ Agnes Leu $\mathbb{D}^{2,3}$ \\ Accepted: 30 August 2021 / Published online: 5 November 2021 \\ (c) The Author(s) 2021
}

\begin{abstract}
Adolescent young carers have been described as a hidden group at risk of mental health problems. However, research has not yet clarified the effect of caring when considering the related family situation. We aimed to examine the impact of a caring role on adolescents' mental health and to gain knowledge about adolescent young carers' specific needs. We collected crosssectional data from adolescents (15-21 years, $N=2525)$ recruited through educational institutions in German-speaking Switzerland. Based on self-reported answers regarding the presence or absence of a family member with health problems and youth's caring activities, the participants were grouped into three subsamples. We compared mental health outcomes (wellbeing and perceived stress) in current carers and their peers, and we conducted multiple regression analyses for predicting these outcomes among all adolescents and the subsample of carers. Adolescent young carers had lower levels of well-being and higher levels of perceived stress than their peers. However, when controlling for background variables, well-being levels were lower only when carers were compared to adolescents from a healthy family background. Indicators of family instability predicted mental health outcomes independently of being a carer. More recognition for the caring role predicted better well-being and perceived stress outcomes, and more support in caring predicted better well-being but not perceived stress outcomes. The findings suggest that a caring role is not necessarily related to decreased well-being in adolescents, but it is associated with higher levels of perceived stress. The way professionals and services respond to young carers' specific needs should be improved.
\end{abstract}

Keyword Adolescent young carers $\cdot$ Youth adjustment $\cdot$ Health $\cdot$ Caregiving $\cdot$ Stress

\section{Highlights}

- This study contributes to the understanding of the impact of a caring role on adolescents.

- Adolescents with a caring role reported poorer mental health outcomes than their peers.

- Differences seem partly attributable to the family situation, i.e., a family member with health problems, instabilities.

- The caring role likely adds extra burden in the form of perceived stress.

- Adolescent young carers have specific needs for support and recognition.

Supplementary information The online version contains supplementary material available at https://doi.org/10.1007/s10826021-02097-w.

Hannah Wepf

hannah.wepf@uzh.ch

1 Department of Psychology, University of Zurich, Binzmühlestrasse 14/Box 7, 8050 Zurich, Switzerland

2 Careum School of Health, Kalaidos University of Applied Sciences, Gloriastrasse 18a, 8006 Zurich, Switzerland

3 Institute for Biomedical Ethics, University of Basel, Bernoullistrasse 28, 4056 Basel, Switzerland
Young carers are youth who assume caring responsibilities for a relative or other close person with a health problem, such as a chronic condition, mental illness, or disability. A substantial proportion of youth grow up with a family member with health problems; however, the exact prevalence of those who assume caring tasks for this person, thus referred to as young carers, is uncertain. International estimates suggest that about 6-22 percent of all children and adolescents are young carers (e.g., Joseph et al., 2019; Leu et al., 2019; Metzing et al., 2020; Robison et al., 2020). Young carers hold rewarding but also highly demanding responsibilities (e.g., Nickels et al., 2018; 
Stamatopoulos, 2018). However, given the low awareness of youth's caring roles among professionals and the general population in most countries, many young carers remain unnoticed and lack support (Nap et al., 2020). Furthermore, a growing population of older adults, along with healthcare trends toward outpatient rather than inpatient treatments, and advances in medical technology will likely result in a rising number of family carers, including young carers (e.g., Perrig-Chiello et al., 2010; Stamatopoulos, 2015). Therefore, it is becoming progressively important to understand how we can address the needs of young carers and their families.

A caring role influences youth's lives in various wayspositively and negatively (Joseph et al., 2009). Concerning mental health, scholars have highlighted risks for potential adverse outcomes due to caring (e.g., Dharampal \& Ani, 2020). However, the small number of comparative studies, broad age ranges, and a lack of theoretical foundation limit the understanding of the observed association between youth's carer role status and mental health. Essentially, few studies have examined the impact of caring on youth's mental health when considering the related family situation. However, such an approach would be needed to examine associations between caring and outcomes. The present study is guided by considerations of a role theory perspective and addresses this gap. Specifically, we investigated mental health outcomes-well-being and perceived stress-in a sample of adolescent young carers aged 15-21 years with ongoing regular and substantial caring tasks as compared to their peers without such caring role. Since previous research has shown that caring by youth is not limited to the traditional nuclear family (e.g., Ali et al., 2015), adolescent young carers in this study may provide care to a relative or other person close to them, such as a friend or neighbor they feel close or committed to.

In any life phase, adopting caring responsibilities for a close person who needs support due to health problems impacts an individual's development and well-being (Shifren, 2009). While adult family carers' mental health has received substantial attention in research, the group of younger carers has been largely overlooked (e.g., Cipolletta et al., 2020). Adolescence is a particularly challenging period and critical for development and well-being in later life (Johnson et al., 2011). Adolescent young carers are characterized by their additional caring tasks and responsibilities, which other youth of their age do not have. Taking into account that helping and supporting others is a natural part of social interactions, caring is commonly understood as ranging on a continuum (Becker, 2007). However, youth's caring activities may be understood in terms of a social role when they regularly and substantially take on caring responsibilities for a person with health problems.
It was proposed that role strain related to caring is a vital aspect for understanding the burden and variability in the outcomes of caring (Bastawrous, 2013). Role theory posits that individuals have various roles in life which affect their behavior and experiences (e.g., Hindin, 2007). While it is assumed that one has multiple roles, certain roles or the combination of different roles can cause role strain, including experienced role conflicts and role overload. Managing a caring role as an adolescent can variously lead to role strain with potential negative impacts on their mental health.

The caring role may pose challenges young people usually are not prepared for in our society (Siskowski, 2009). Besides helping with daily domestic and household tasks that the person cared for may not be able to do (e.g., grocery, cleaning, looking after siblings), young carers typically also assume more complicated, less 'normative' tasks. These include personal care tasks (e.g., help with eating, walking, showering, medication, wound care, injections), administrative and coordinative tasks (e.g., fill out forms, schedule appointments and transportation, talk to health professionals, organize aids), as well as emotional and social support (e.g., cheer up, calm, or accompany the person; make sure she/he is safe; e.g., Joseph et al., 2009). Such tasks require skills and resources that youth usually are not equipped with. Unsurprisingly, many young carers are proud of their acquired skills and attach value to their competencies (e.g., McDougall et al., 2018; Stamatopoulos, 2018).

However, the process of developing the skills and confidence to provide care is challenging. As care needs of the recipient may change over time, adolescents can find themselves in a new difficult situation, and they must acquire knowledge in how to solve them. If the perceived requirements outreach their resources to manage, youth can experience enduring or re-occurring role overwhelm. Likewise, qualitative research underlined that young carers often experience feelings of worry, constant alertness, and vigilance linked to their caring tasks (Ali et al., 2012; McDougall et al., 2018; Nickels et al., 2018).

Besides the demands of the caring role itself, caring responsibilities can interfere with adolescents' other roles (McDougall et al., 2018; Stamatopoulos, 2018). A recent cross-country study showed that adolescent young carers (aged 15-17 years) spend on average four hours caring per day (Santini et al., 2020). This figure underlines that a caring role requests a lot of time and energy of the adolescents and, thereby, leaves them limited resources for other life domains, such as friends and school (for an overview, see Leu \& Becker, 2019). Thus, the combination of roles can cause role overload. That is, when young carers feel that they cannot manage all the expectations of their multiple roles. Moreover, the different roles may cause 
conflicts when they imply contradictory or incompatible expectations. Likewise, youth's higher levels of caring responsibility were associated with more perceived restrictions for study/work and other life domains (Pakenham \& Cox, 2015). Also, young carers' high levels of absenteeism at school/work may reflect such conflicts (e.g., Becker \& Sempik, 2019). Stamatopoulos (2018) impressively described the emotional consequences, including extreme outbursts of anger, sadness, and disappointment, that some of the interviewed young carers experienced when they could not complete educational assessments on time. This finding underlines the impact of role conflicts on young carers' mental health. In sum, caring can leads to role strain in adolescents, on the one hand, due to the demands of the caring role, and, on the other hand, due to the multitude of the roles they hold.

Role combinations that are uncommon or not obvious to others, such as when adolescents have a caring role in addition to their student role, likely facilitate role strain. Sometimes youth themselves are not aware of their particular role, or they wish not to disclose their caring (e.g., McDougall et al., 2018; Smyth et al., 2011). In other situations, their environment, including teachers and peers, simply does not recognize or understand their situation. Having caring responsibilities that are unknown to others may have negative consequences for the adolescents. For instance, teachers or vocational trainers may misinterpret their mental or physical absence as disengagement or disinterest instead of tiredness or worry due to caring tasks (Becker \& Becker, 2008). Moreover, peers may not understand their situation and behavior, leaving young carers to feel emotionally lonely and socially isolated (e.g., Stamatopoulos, 2018). Lakman and Chalmers (2019) found that young carers reported lower quality of attachment to their friends and more bullying directed at them than matched noncarers.

The lack of support and recognition for their caring role likely increases the challenges of young carers. When young carers' environment knows about their caring role, they may help them anticipate role overwhelm or solve conflicts. Similarly, young carers in a UK study verbalized that the understanding and appropriate support from school staff and friends made a significant difference for them (Becker \& Becker, 2008). Cassidy et al. (2014) found a negative association between young carers' perceived social recognition of the role and stress appraisal. Moreover, interviews with young carers and their care recipients emphasized the importance that professionals help young carers in balancing education and caring (Frech et al., 2021). However, presently, many young carers in Switzerland, as in other countries, are not recognized and supported as such (Leu et al., 2020; Nap et al., 2020). Consequently, combining a student, peer, and a young carer role, often bears significant difficulties in youth's day-to-day lives.
Several studies support the view that caring can lead to negative emotional experiences among youth. The findings showed that compared to peers without a caring role, young carers reported poorer overall mental health (Tseliou et al., 2018: aged 5-24 years; Robison et al., 2020: aged 11-18 years); and more symptoms of depression and anxiety (Greene et al., 2017: aged 18-24 years; mean age: 12 years: Lakman \& Chalmers, 2019: aged 8-18+ years). Another study found that young carers reported lower levels of life satisfaction than peers (Haugland et al., 2019: aged 18-25 years). To our knowledge, only two studies have compared perceptions of stress between young carers and their peers. Charles (2019) analyzed data derived from the Canadian 2013 British Columbia Adolescent Health Survey (grades 7-12) and found that young carers reported higher rates of extreme stress than their peers (12 vs. $9 \%$; single item measure). Hawken (2019) compared indicators of stress between young carers and noncarers (aged 11-18 years). This small-scale comparison study did not find group differences regarding hair cortisol, a biological stress marker. However, differences in self-reported perceived stress were significant, suggesting higher levels among young carers. In sum, a growing body of literature showed that being a young carer is associated with poorer mental health outcomes. However, most of these studies have grouped together young carers of broad age ranges, thus making it impossible to extract evidence on the extent of outcomes in the specific age group of adolescents.

Moreover, there remains uncertainty why there are differences between young carers and their peers for two main reasons. First, it remains unknown to what extent the observed tendency to manifest adverse outcomes among young carers is caused by being in a caring role when considering the potential influence of a family member's health problems per se. Growing up with a family member who has an illness or disability has been associated with various negative outcomes in adolescents, such as physical and emotional problems, stress, and problem behavior (e.g., Pakenham \& Cox, 2014; de Roos et al., 2017; Sieh et al., 2013). Pakenham and Cox (2014) found that the association between youth's caring responsibilities and adjustment outcomes was largely independent of the presence of a serious illness in the family, suggesting that caring may have a specific effect beyond family health problems. However, the unique effect of a considerable caring role has not yet been further addressed in research. Examining mental health differences in adolescents with a substantial caring role compared to their peers affected by a close person's health problems but without substantial caring responsibilities and those from a healthy family background in one study may provide clarity.

Second, the designs of prior studies make it impossible to separate the effect of caring from further family-related aspects. 
Youth's caring often occurs in the context of unstable family situations, such as low socioeconomic status or single-parent households (e.g., Lakman \& Chalmers, 2019; Levine et al., 2005). Family is an essential resource for youth, and instabilities in the family situation, such as economic hardship or a disruption of the family structure, pose general risks for youth's well-being and development (Brown, 2010; Conger et al., 2010; Crosnoe \& Cavanagh, 2010). A few studies have included indicators for the socioeconomic background as covariates when comparing mental health outcomes between young carers and their peers. These studies showed that poorer outcomes among young carers could not be explained by family context variables only (e.g., Haugland et al., 2019; Tseliou et al., 2018). However, viewed from an ecological perspective, development in different areas, including mental health, results from the interactions between the person and the environment (e.g., Tomasetti, 2016). Therefore, family instability characteristics may not only impact negatively on young carers' mental health, but such circumstances could also increase the negative impact of caring. Economic instabilities, such as financial problems or parental unemployment, can be associated with the family's ability to afford professional services for care (e.g., home care, transport, and respite care). Structural instabilities in terms of the absence of reliable and consistent adults in the household (e.g., due to parental divorce, separation or, death of a family member) place a higher burden of responsibility on the children and adolescents, especially when someone has care needs. Whether there is an interaction between an adolescent's caring role and the family context has not been addressed. Therefore, it remains unknown to what extent young carers' risk for experiencing mental health difficulties results from their family context, their caring role, or the combination of both.

\section{The Present Study}

The understanding of why adolescent young carers demonstrate poorer mental health than peers is limited. To advance the field, research must embed empirical work into theories and unravel the impact of caring from other contextual factors. The present study addressed these gaps. Coming from a role perspective, we aimed to compare current adolescent young carers (AYC) to their peers that did not have a caring role. In contrast to previous studies, we included two comparison groups, namely adolescents with a family member who has a health problem but who did not report substantial and regular caring activities (FHP) and adolescents from a healthy family background (HF). Figure 1 illustrates the scheme of how the groups were defined. We predicted that AYC participants would report lower levels of well-being and higher levels of perceived stress than participants in both comparison groups, FHP and HF (Hypothesis 1 and 2). We further predicted that the differences between AYC participants and their peers (FHP and HF participants) would not be exclusively attributable to caring but rather to the interaction of an adolescents' carer role status and indicators of family instability (economic hardship or disrupted family structure; Hypothesis 3 and 4). Finally, we addressed two factors that may lower strain related to adolescents' caring roles. To this end, we hypothesized that more support for their role as a carer and more recognition of the caring role would be
Fig. 1 Groups of adolescents compared in this study defined based on their family members' health and the caring activities adolescents performed
Family health problems:

Presence of a close person who needs support in daily life because of a health problem such as an illness, mental health problems, disabilities, infirmities of old age, addiction, or injury needs?

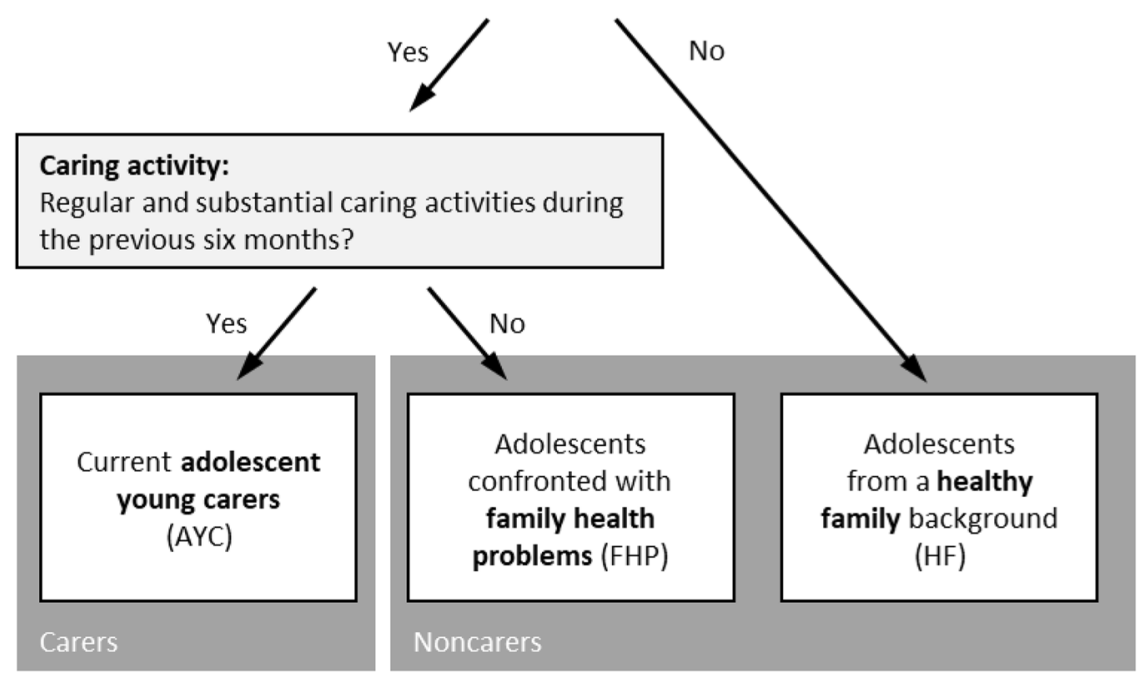


associated with higher levels of well-being and lower levels of perceived stress (Hypothesis 5 and 6).

\section{Method}

\section{Participants and Procedure}

The study sample consisted of 2525 adolescents aged 15 to 21 years attending school or vocational training in the German-speaking part of Switzerland - Table 1 entails further information on the characteristics of the sample. We applied a two-step sampling method. To minimize the risk of selection bias, we included youth from clusters of participating schools or companies. In step one, we asked 19 schools and one company offering vocational training if they would participate in our study. Seven schools and one company agreed to support the research project. In step two, the participating institutions invited their students and trainees to participate in the survey.

Before data collection, directors, (head) teachers, and trainers were informed about the purpose and procedure of the study. Along with their agreement to participate in the study, institutions received information sheets for the potential participants, letters for their parents, and the materials required to conduct the survey (i.e., brief guidelines including the link to access the online survey). Data collection was carried out between May 2018 and November 2019. Prior to completing the survey, adolescents were informed about the study aim, confidentiality issues, and the voluntary nature of participation. Completing the online survey took approximately $25 \mathrm{~min}$ and was administered during school or working hours or as a home assignment. The participants were not compensated. This study was approved by the Research Ethics Committee, Faculty of Arts and Social Sciences, University of Zurich (No: 2018.2.6).

\section{Measures}

\section{Demographics and education}

Adolescents answered questions regarding their age (in years), gender, and nationality. They also provided information about the type of their current education.

\section{Caring context}

Identifying adolescent young carers is challenging. There is no established term for' young carers' in Swiss German
Table 1 Background and outcome variables of the overall study sample and by carer role status groups

\begin{tabular}{|c|c|c|c|c|}
\hline & \multirow{2}{*}{$\begin{array}{l}\text { Overall } \\
(N=2525)\end{array}$} & \multirow{2}{*}{$\begin{array}{l}\text { Carers } \\
\text { AYC }(n=405)\end{array}$} & \multicolumn{2}{|l|}{ Noncarers } \\
\hline & & & $\mathrm{FHP}(n=782)$ & $\mathrm{HF}(n=1338)$ \\
\hline Gender, \% [CI] female & $59.6[57.7,61.5]$ & $70.4[65.8,74.6]$ & $63.9[60.5,67.2]$ & $53.8[51.1,56.5]$ \\
\hline Age in years, $M(\mathrm{SD})$ & $17.73(1.55)$ & $17.91(1.57)$ & $17.76(1.56)$ & $17.65(1.53)$ \\
\hline Nationality, \% [CI] Swiss & $71.5[69.7,73.2]$ & $68.4[63.7,72.7]$ & $72.9[69.7,75.9]$ & $71.5[69.1,73.9]$ \\
\hline \multicolumn{5}{|l|}{ Education, $\%[\mathrm{CI}]$} \\
\hline General education & $8.3[7.3,9.5]$ & $8.2[5.9,11.2]$ & $7.4[5.8,9.5]$ & $8.9[7.5,10.5]$ \\
\hline VET & $85.6[84.2,86.9]$ & $83.0[79.0,86.3]$ & $87.1[84.6,89.3]$ & $85.5[83.5,87.3]$ \\
\hline Transitional options & $2.9[2.3,3.6]$ & $4.4[2.8,6.9]$ & $2.2[1.4,3.5]$ & $2.8[2.0,3.8]$ \\
\hline Other & $3.2[2.6,4.0]$ & $4.4[2.8,6.9]$ & $3.3[2.3,4.8]$ & $2.8[2.1,3.9]$ \\
\hline \multicolumn{5}{|l|}{ Family instability, \% [CI] } \\
\hline Structure & $52.2[50.3,54.2]$ & $63.0[58.2,67.5]$ & $58.1[54.6,61.5]$ & $45.6[42.9,48.3]$ \\
\hline Economic & $38.7[36.8,40.6]$ & $52.6[47.7,57.4]$ & $41.4[38.0,44.9]$ & $32.8[30.4,35.4]$ \\
\hline Life events, $M(\mathrm{SD})$ & $7.71(4.91)$ & $10.17(5.16)$ & $8.82(5.14)$ & $6.31(4.18)$ \\
\hline Well-being, $M$ (SD) & $50.89(8.76)$ & $49.14(8.51)$ & $50.34(8.90)$ & $51.74(8.66)$ \\
\hline Perceived stress, $M(\mathrm{SD})$ & $20.32(6.24)$ & $22.95(5.93)$ & $20.62(6.22)$ & $19.35(6.10)$ \\
\hline \multicolumn{5}{|l|}{ Caring role } \\
\hline Responsibility, $M$ (SD) & & $25.12(6.58)$ & & \\
\hline Recognition $M$ (SD) & & $20.74(4.48)$ & & \\
\hline Support, $M(\mathrm{SD})$ & & $19.87(4.81)$ & & \\
\hline $\begin{array}{l}\text { Onset as a child, } \%[\mathrm{CI}] \\
\text { (younger than } 13 \text { years) }\end{array}$ & & $35.3[30.8,40.1]$ & & \\
\hline
\end{tabular}

$A Y C$ adolescent young carers, $F H P$ adolescents confronted with family health problems, $H F$ adolescents from a healthy family background, CI $95 \%$ confidence intervals for binomial proportions following the Wilson method, VET vocational education and training, General education specialized or a baccalaureate school, Structure disrupted family structure, Economic economic hardship 
nor an official or legal definition (Frech et al., 2019; Wepf et al., 2017). Previous studies have highlighted that young people often perceive their caring role as 'normal' or that they reject labeling it (Leu et al., 2018; Smyth et al., 2011). In other words, using a question that directly asks youth whether they are carers or not would likely lead to a bias. Therefore, we used a set of questions to identify adolescents with a caring role.

All participants were asked whether a person they felt close to needed support in daily life because of health problems such as an illness, mental health problems, disabilities, infirmities of old age, addiction, or injury needs. Then, filters were used to let the participants skip certain questions according to their situation. In cases in which the participants reported that there were multiple persons with health problems, they were to choose the person being most significant in their current life. Participants were asked to provide further information about the person in need of support to assess the carer's relationship to the care recipient (mother, father, brother, sister, etc.) and living situation (living together, partly living together, not living together), as well as the care recipient's gender, type of health problems (multiple answer format: physical; mental; cognitive, or other difficulties) and need for support using 4-point scales $(0=$ no help; $3=$ a lot of help $)$.

The frequency of adolescents' caring tasks was assessed across four domains of care: domestic/household (e.g., cleaning, grocery shopping, cooking, looking after siblings, etc.), personal/nursing (e.g., help with eating, washing, or toileting, help with medication, etc.), social/emotional (e.g., cheering up, keeping company, make sure the person is safe, accompany, etc.), and instrumental/administrative (e.g., coordination of appointments, paying bills, doing phone calls, organizing transportation, etc.). For each domain, the participants rated on a 5 -point scale $(1=$ never, $2=$ rarely, $3=$ now and then, $4=$ often, $5=$ very often $)$ how often they had carried out these caring tasks during the past six months. In addition, they indicated how much time they had spent caring for the person in an average week separately for each of the four domains. Furthermore, information was obtained on participants' age (in years) when they first started supporting the care recipient.

\section{Caring experience}

Three aspects of young carers' subjective experiences of the caring situation were assessed: recognition of their carer role, support for themselves as carers, and caring responsibility. Items from existing instruments (further information and references are provided below) were translated from English into German by two independent researchers. The versions were subsequently discussed in the research team to find a consensus. To ascertain item comprehension and the suitability of the vocabulary, we then administered the harmonized version to a small group of young carers. No changes to the translated items were made at this stage. The items on the scales were mixed and presented in randomized order. A 6-point scale $(1=$ strongly disagree, $6=$ strongly agree) was used.

Social recognition of the carer role was assessed using a scale that included two translated items from the Social Recognition of Role subdimension of the Young Carers Perceived Stress Scale (YCPSS; Cassidy \& Giles, 2013; i.e., "The people that I know understand about my caring," reversed coded: "It bothers me that people never say they are pleased with my caring") and three newly formulated items. Two of the new items covered perceived appreciation for the adolescent's support expressed by either family and friends or by the care recipient. The third covered adolescents' perceived recognition of their caring role by people at school or training place. After reversing the negatively stated item scores, we determined the perceived recognition of the carer role score by computing the total for all five items. The internal consistency of the scale was $\alpha=0.61$.

Perceived support for the carers themselves was measured using a German translation of the Support for Caring subscale of the Adult Carer Quality of Life questionnaire (AC-QoL; Joseph et al., 2012). The mean score was obtained by computing the mean response across all five items. Higher scores indicated a higher level of perceived support for caring. The scale demonstrated acceptable internal consistency $(\alpha=0.73)$.

Caring responsibility was assessed using seven items, which were translated and adapted from the Young Caregiver of Parents Inventory (YCOPI) by Pakenham et al. (2006). The items were rephrased to make them applicable to all young people regardless of whether the care recipient is a parent, sibling, friend, or another close person. For this reason, one item from the original 8-item version ("I have to look after my other family members") was excluded. The scale demonstrated acceptable internal consistency $(\alpha=0.74)$.

\section{Life events and family instability}

Critical life events in youth's past were assessed based on a list of 26 events sampled from multiple domains: family (e.g., "change in family composition" or" financial problems"), school/career (e.g., "grade repeated" or "dropped out of a training/school"), interpersonal (e.g., "break up" or "mobbing"), and personal (e.g., "addiction problems" or "accident"). The development of the instrument was based on pre-existing instruments (i.e., Low et al., 2012; Neuenschwander, 1998). The participants were asked if they had experienced each situation $(0=n o ; 1=y e s)$. We computed the total score across all life events experienced. 
Family instability was operationalized based on family domain items in the abovementioned instrument. We derived dichotomous variables as indicators for disrupted family structure (coded 1 if youth reported "divorce or separation of parents", "change of family composition", and/or "death of a family member") and economic hardship (coded 1 if youth reported "financial problems within the family" and/or "unemployment of a parent").

\section{Well-being}

Well-being was assessed using the German version of the Warwick-Edinburgh Mental Well-being Scale (WEMWBS; Lang \& Bachinger, 2017; Tennant et al., 2007). All items were rated on 5-point scales ( $1=$ none of the time, $5=$ all of the time). The total score was derived by summing up the responses across all 14 items. Higher scores indicate higher levels of well-being. Cronbach's $\alpha$ in the present study was $\alpha=0.89$.

\section{Perceived stress}

Perceived stress was measured using a German 10-item version of the Perceived Stress Scale (PSS-10; Cohen et al., 1983; Klein et al., 2016). All items were answered on 5 -point scales $(1=$ never, $5=$ always $)$. After reversing the scores on the four positively stated items (items 4, 5, 7, and 8), a PSS-10 total score was obtained by summing the responses across all ten items. Higher scores indicated a higher level of perceived stress. Cronbach's $\alpha$ in the present study was $\alpha=0.78$.

\section{Analytical Approach}

We screened data using IBM SPSS Statistics 24 and conducted all statistical analyses in $\mathrm{R}$ software. The online survey settings did not allow respondents to skip questions. Incomplete surveys in terms of dropout were excluded case-wise $(n=142)$, resulting in an analysis dataset without missing values. Cases were flagged when there was an indication for response bias throughout the survey (e.g., outliers in terms of the participants responding carelessly or exhibiting comprehension problems, $n=69$ ). We conducted robustness checks to test whether the exclusion of the flagged cases resulted in changes in the results. As the differences were trivial, we reported the results based on the entire dataset.

\section{Grouping variable}

Responses from the caring context questionnaire section were combined to create a carer role status variable $(1=A Y C, 2=F H P$, or $3=H F)$. Adolescents reporting regular and substantial caring tasks during the previous six months for a person close to who needed support due to health problems were classified as AYC. It was required that caring tasks of at least one domain were carried out regularly (i.e., reflected in the time spent per week $>0 \mathrm{~min}$ ) and substantially, that is, a) domestic/household care: often, b) personal/nursing care: now and then, c) social/emotional care: very often, or d) instrumental/administrative care: now and then.

The remaining participants were either assigned to the FHP group if they reported that a person close to them had health problems, but they did not support that person substantially and regularly during the preceding six months, or to the HF group if they indicated that no person who they were emotionally close to had health problems.

Our group definitions are consistent with a liberal young carer definition-including lower levels of caring if care activities occur regularly-and based on a broad conceptualization of family beyond the nuclear family. We believe this definition to be adequate for the contemporary context and purpose of our study. However, for interested scholars working with a more traditional family definition, we performed additional analyses using a narrower definition of family members (i.e., family relationships are parents, siblings, and grandparents). We included the corresponding tables in the supplementary material section (see A1).

\section{Statistical models}

Bivariate and multivariate analyses were performed. Regarding Hypothesis 1 and 2, we first conducted Welch $t$-tests for independent groups to assess differences in well-being and perceived stress between carers (AYC) and noncarers $(\mathrm{FHP}+\mathrm{HF})$. Multivariate regression analyses for predicting well-being and perceived stress among the overall sample were then used. They allowed us to test whether differences remained after controlling for relevant background variables (demographics and family context) and to test for the proposed interaction effects of carer role status and family instability indicators (Hypothesis 3 and 4). For these analyses, we produced dummy variables, meaning that we used a variable that had a value of either 0 or 1 to indicate the absence or presence of the variable in question, respectively. This approach allowed us to compare the data from FHP or HF groups (comparison groups = 1) with the data from the AYC group (target group $=0$ ) for both outcome variables separately. To test for interaction effects, we combined the data from FHP and HF groups (comparison groups = 1) and compared those data with those of the AYC group (target group $=0$ ) for both outcome variables separately. Hypothesis 5 and 6 were also tested using multivariate hierarchical regression analyses for predicting well-being and perceived stress, but only using the AYC subsample. 


\section{Results}

\section{Demographic Group Characteristics and Differences}

Of the total of 2525 adolescents, $47 \%$ reported that there was someone they felt close to and who was affected by health problems. Among those, 405 (16.0\% of the overall sample) adolescents met our young carer criteria and were thus assigned to the AYC group. Table 1 shows the characteristics of the subgroups separately. Comparisons regarding group characteristics illustrated that the demographic characteristics differed between groups regarding age and gender. AYC participants were slightly older than adolescents from the HF group. The proportion of females was higher among AYC and FHP participants than among HF participants. AYC participants had experienced more critical life events than FHP and HF participants, and FHP participants had experienced more critical life events than HF participants. In addition, the percentage of participants having experienced economic hardship and a disrupted family structure differed by carer role status. Participants in the AYC group were more likely to have experienced family instability (across both indicators) compared to those in the HF group, and they were also more likely to have experienced economic hardship but not a disrupted family structure compared to those in the FHP group. For both indicators, there were group differences between FHP and HF participants, suggesting that having a family member with health problems was associated with more adversity. These group characteristics are similar to those in previous samples (Lakman \& Chalmers, 2019; de Roos et al., 2017; Tseliou et al., 2018).

Regarding the (main) care recipient, AYC participants most frequently $(44.2 \%)$ supported a member of the nuclear family (i.e., $31.9 \%$ supported a parent and $12.4 \%$ supported a sibling), 19.8\% supported a grandparent, $7.2 \%$ supported another relative (e.g., an aunt or uncle), and $27.1 \%$ supported a friend (including the $7.7 \%$ who supported a girlfriend/boyfriend). A total of $1.5 \%$ wished not to specify who the person was. Almost half of the AYC participants (46.4\%) reported that the health problem of the care recipient was mental/cognitive difficulty; in $31.4 \%$ of the cases, the health problem was a solely physical difficulty, and in $22.2 \%$ of the cases, the problem was a combination of physical and mental/cognitive difficulties. More than half of the AYC participants $(54.8 \%)$ lived with the care recipient (42.2\% all of the time, $12.6 \%$ partly).

\section{Effects of a Caring Role on Adolescents' Well-being and Perceived Stress}

We expected that the caring role would be associated with emotional disturbance and additional stress experienced in adolescents' day-to-day lives (Hypothesis 1 and 2). The group comparisons revealed the well-being mean score among carers $(M=49.14, \mathrm{SD}=8.51)$ was lower than among noncarers $(M=51.22, \mathrm{SD}=8.77), t(580.01)=$ $-4.48, p<0.001, d=0.24$. The results of the hierarchical multiple regression analyses of caring role status as predictors of well-being and perceived stress among adolescents when controlling for demographics and family instability are shown in Table 2 . The results confirmed that belonging to the HF group compared to belonging to the AYC group served as a predictor of well-being scores when controlling for demographics and family instability indicators $(t(2517)=3.48, p<0.001)$. The difference in the mean well-being score between FHP and AYC participants diminished after controlling for demographics and family instability indicators and was no longer significant $(t(2517)=1.43, p=0.154)$. Furthermore, gender $(t(2517)=5.71, p<0.001)$, nationality $(t(2517)=-4.45$, $p<0.001)$, and economic hardship $(t(2517)=-5.59, p<$ $0.001)$ significantly predicted well-being scores among adolescents, and regression coefficients indicated that being female, non-Swiss, and having experienced economic family instability was associated with poorer levels of well-being among adolescents. As such, the results did only partially confirm Hypothesis 1 . The findings suggest adolescents' caring role does not necessarily add emotional disturbance in their day-to-day lives given a family member with health problems.

With regard to perceived stress, carers $(M=22.95$, $\mathrm{SD}=5.93$ ) also reported poorer outcomes, that is, higher levels of perceived stress than non-carers $(M=19.82$, $S D=6.18), \quad t(584.33)=9.69, \quad p<0.001, d=0.51$. The results from the hierarchical multiple regression analyses (shown in Table 2) confirmed that when compared to being an AYC participant, belonging to the HF group $(t(2517)=$ $-7.85, p<0.001)$ or to the FHP group $(t(2517)=-5.31$, $p<0.001)$ significantly predicted lower perceived stress after controlling for demographics and indicators of family instability. In addition to carer role status, gender $(t(2517)=$ $-12.27, p<0.001)$ and the experience of a disrupted family structure $(t(2517)=2.19, p=0.029)$ as well as economic hardship $(t(2517)=7.03, p<0.001)$ significantly predicted perceived stress scores among adolescents. The regression coefficients indicated that being female, having experienced economic hardship and having a disrupted family composition were associated with higher levels of perceived stress. As such, the findings confirm Hypothesis 2 and thus support that a caring role impacts adolescents' mental health in the form of added stress.

To address the potential interplay between carer role status and family instabilities, we performed further regression analyses, the results of which are shown in Table 3. In contrast to our prediction (Hypothesis 3 and 4), 
Table 2 Multiple regression of caring role status as predictors of well-being and perceived stress among adolescents when controlling for demographics and family instability

\begin{tabular}{|c|c|c|c|c|c|c|c|c|}
\hline \multirow[b]{2}{*}{ Predictors } & \multicolumn{4}{|c|}{ Well-being } & \multicolumn{4}{|c|}{ Perceived stress } \\
\hline & $\Delta R^{2}$ & $B$ & SE $B$ & $\beta$ & $\Delta R^{2}$ & $B$ & SE $B$ & $\beta$ \\
\hline Intercept & & $48.28 * * *$ & 2.02 & & & $22.68 * * *$ & 1.39 & \\
\hline Carer role status (ref. AYC) & $0.01 * * *$ & & & & $0.04 * * *$ & & & \\
\hline FHP & & 0.75 & 0.53 & 0.04 & & $-1.91 * * *$ & 0.36 & -0.14 \\
\hline $\mathrm{HF}$ & & $1.72 * * *$ & 0.50 & 0.10 & & $-2.66^{* * *}$ & 0.34 & -0.21 \\
\hline Demographics & $0.02 * * *$ & & & & $0.06 * * *$ & & & \\
\hline Gender (ref. $=$ female) & & $2.01 * * *$ & 0.35 & 0.11 & & $-2.95 * * *$ & 0.24 & -0.23 \\
\hline Age & & 0.13 & 0.11 & 0.02 & & -0.01 & 0.08 & -0.00 \\
\hline Nationality (ref. $=$ Swiss) & & $-1.70 * * *$ & 0.38 & -0.09 & & 0.34 & 0.26 & 0.03 \\
\hline Family instability & $0.02 * * *$ & & & & $0.02 * * *$ & & & \\
\hline Structure & & -0.65 & 0.35 & -0.04 & & $0.53 *$ & 0.24 & 0.04 \\
\hline Economic & & $-2.05 * * *$ & 0.37 & -0.11 & & $1.77 * * *$ & 0.25 & 0.14 \\
\hline Explained variance & & $R^{2}=0.05 /$ & ${ }^{2}{ }_{\text {adj }}=$ & .05 & & $R^{2}=0.12 /$ & ${ }^{2}$ adj $=$ & .12 \\
\hline$F$-test & & $F(7,2517)$ & $=19.5$ & **** & & $F(7,2517)$ & $=50.18$ & *** \\
\hline
\end{tabular}

$N=2525$

$A Y C$ adolescent young carers, $F H P$ adolescents confronted with family health problems, $H F$ adolescents from a healthy family background, Structure disrupted family structure, Economic economic hardship $* p<0.05 ; * * p<0.01 ; * * * p 0.001$

Table 3 Multiple regression of carer role status, and family instability indicators, and interaction term as predictors of well-being and perceived stress

\begin{tabular}{|c|c|c|c|c|c|c|c|c|c|c|c|c|}
\hline \multirow[b]{3}{*}{ Predictors } & \multicolumn{6}{|l|}{ Well-being } & \multicolumn{6}{|c|}{ Perceived stress } \\
\hline & \multicolumn{3}{|c|}{ Interaction model A } & \multicolumn{3}{|c|}{ Interaction model B } & \multicolumn{3}{|c|}{ Interaction model A } & \multicolumn{3}{|c|}{ Interaction model B } \\
\hline & $B$ & $\mathrm{SE} B$ & $\beta$ & $B$ & SE $B$ & $\beta$ & $B$ & SE $B$ & $\beta$ & $B$ & SE $B$ & $\beta$ \\
\hline Intercept & $49.71 * * *$ & 1.97 & & $49.79 * * *$ & 1.97 & & $20.17 * * *$ & 1.35 & & $20.22 * * *$ & 1.35 & \\
\hline \multicolumn{13}{|l|}{ Covariates } \\
\hline Gender $($ ref. $=$ female $)$ & $2.08 * * *$ & 0.35 & 0.12 & $2.07 * * *$ & 0.35 & 0.12 & $-3.01 * * *$ & 0.24 & -0.24 & $-3.01 * * *$ & 0.24 & -0.24 \\
\hline Age & 0.12 & 0.11 & 0.02 & 0.12 & 0.11 & 0.02 & -0.01 & 0.08 & -0.00 & -0.01 & 0.08 & -0.00 \\
\hline Nationality (ref. $=$ Swiss) & $-1.69 * * *$ & 0.38 & -0.09 & $-1.68 * * *$ & 0.38 & -0.09 & 0.32 & 0.26 & 0.02 & 0.33 & 0.26 & 0.02 \\
\hline \multicolumn{13}{|l|}{ Main effects } \\
\hline Structure (ref. no) & -0.66 & 0.38 & -0.04 & $-0.73 *$ & 0.35 & -0.04 & $0.65^{*}$ & 0.26 & 0.05 & $0.59 *$ & 0.24 & 0.05 \\
\hline Economic (ref. no) & $-2.10^{* * *}$ & 0.37 & -0.12 & $-2.21 * * *$ & 0.40 & -0.12 & $1.81 * * *$ & 0.25 & 0.14 & $1.78 * * *$ & 0.28 & 0.14 \\
\hline Carer role status (ref. not AYC) & -1.06 & 0.75 & -0.04 & $-1.66^{*}$ & 0.66 & -0.07 & $2.62 * * *$ & 0.51 & 0.15 & $2.29 * * *$ & 0.46 & 0.14 \\
\hline \multicolumn{13}{|l|}{ Interaction } \\
\hline Carer role status $\times$ structure & -0.46 & 0.96 & -0.02 & & & & -0.41 & 0.66 & -0.02 & & & \\
\hline Carer role status $\times$ economic & & & & 0.66 & 0.94 & 0.02 & & & & 0.15 & 0.64 & 0.01 \\
\hline Explained variance & \multicolumn{3}{|c|}{$R^{2}=0.05 / R_{\mathrm{adj}}^{2}=0.05$} & \multicolumn{3}{|c|}{$R^{2}=0.05 / R_{\mathrm{adj}}^{2}=0.05$} & \multicolumn{3}{|c|}{$R^{2}=0.12 / R_{\mathrm{adj}}^{2}=0.12$} & \multicolumn{3}{|c|}{$R^{2}=0.12 / R_{\text {adj }}^{2}=0.12$} \\
\hline$F$-test & \multicolumn{3}{|c|}{$F(7,2517)=18.59 * * *$} & \multicolumn{3}{|c|}{$F(7,2517)=18.63 * * *$} & \multicolumn{3}{|c|}{$F(7,2517)=48.95^{* * *}$} & \multicolumn{3}{|c|}{$F(7,2517)=48.90^{* * *}$} \\
\hline
\end{tabular}

$N=2525$

$A Y C$ adolescent young carers, Structure disrupted family structure, Economic economic hardship

${ }^{*} p<0.05 ; * * p<0.01 ; * * * p<0.001$

there were no significant interaction effects between carer role status and family instability indicators, suggesting that the co-occurrence of the two characteristics does not seem to harm adolescents' current mental health beyond (for more details, see A2 in the Supplementary Material).

\section{Predictors of Carers' Well-being and Perceived Stress}

The two regression models predicting mental health outcomes in AYC participants are shown in Table 4. Social recognition of the caring role $(t(393)=3.78, p<0.001)$ and 
Table 4 Multiple regression of predictors of well-being and perceived stress among adolescent young carers

\begin{tabular}{|c|c|c|c|c|c|c|c|c|}
\hline \multirow[b]{2}{*}{ Predictors } & \multicolumn{4}{|c|}{ Well-being } & \multicolumn{4}{|c|}{ Perceived stress } \\
\hline & $\overline{\Delta R^{2}}$ & $B$ & SE $B$ & $\beta$ & $\overline{\Delta R^{2}}$ & $B$ & SE $B$ & $\beta$ \\
\hline Intercept & & $22.51 * * *$ & 4.86 & & & $31.87 * * *$ & 3.39 & \\
\hline Background & $0.09 * * *$ & & & & $0.17 * * *$ & & & \\
\hline Gender (ref. $=$ female $)$ & & 1.44 & 0.83 & 0.08 & & $-3.37 * * *$ & 0.58 & -0.26 \\
\hline Age & & $0.74 * *$ & 0.25 & 0.14 & & -0.26 & 0.17 & -0.07 \\
\hline Nationality (ref. $=$ Swiss) & & -1.12 & 0.83 & -0.06 & & -0.22 & 0.58 & -0.02 \\
\hline Life events & & $-0.25 * *$ & 0.08 & -0.15 & & $0.30^{* * *}$ & 0.05 & 0.26 \\
\hline Caring context and role & $0.03 *$ & & & & 0.01 & & & \\
\hline $\begin{array}{l}\text { Relationship to CR (ref. }=\text { not a } \\
\text { parent) }\end{array}$ & & 0.52 & 0.97 & 0.03 & & -0.61 & 0.68 & -0.05 \\
\hline Co-residence $($ ref. $=$ partly or yes) & & $1.86^{*}$ & 0.92 & 0.11 & & -0.73 & 0.64 & -0.06 \\
\hline $\begin{array}{l}\text { Illness/disability } \\
\text { (ref. = physical) }\end{array}$ & & -0.68 & 0.84 & -0.04 & & -0.39 & 0.59 & -0.03 \\
\hline Caring responsibility & & -0.04 & 0.06 & -0.03 & & 0.08 & 0.04 & 0.09 \\
\hline $\begin{array}{l}\text { Onset as child (ref. }=13 \text { years } \\
\text { or older) }\end{array}$ & & $1.74 *$ & 0.81 & 0.10 & & -0.82 & 0.57 & -0.07 \\
\hline Resources for caring & $0.13 * * *$ & & & & $0.06 * * *$ & & & \\
\hline Recognition & & $0.39 * * *$ & 0.10 & 0.21 & & $-0.23 * *$ & 0.07 & -0.18 \\
\hline Support & & $0.38 * * *$ & 0.10 & 0.22 & & -0.12 & 0.07 & -0.10 \\
\hline Explained variance & & $R^{2}=0.24$ & $2^{2}{ }_{\text {adj }}=$ & & & $R^{2}=0.2$ & $2^{2}{ }_{\text {adj }}=0$ & \\
\hline$F$-test & & $F(11,393$ & $=11.3$ & & & $F(11,393$ & $=11.20$ & \\
\hline
\end{tabular}

$N=405$

Life events count of experienced critical life events, $C R$ care recipient, Caring responsibility perceived caring responsibility, Onset as child onset of caring before the age of 13 years, Recognition perceived recognition of caring role, Support perceived support for caring

$* p<0.05 ; * * p<0.01 ; * * * p<0.001$ perceived support for caring $(t(393)=3.86, p<0.001)$ predicted well-being among AYC participants in the expected direction. In addition to these predictors, only age $(t(393)=$ $2.98, p=0.003)$, the number of critical life events experienced $(t(393)=-3.20, p=0.002)$, living apart from the care recipient $(t(393)=2.02, p=0.044)$, and onset of caring during childhood $(t(393)=2.14, p=0.033)$ were significant predictors of well-being among AYC participants in the tested model. Social recognition $(t(393)=-3.18, p=0.002)$ but not perceived support for caring $(t(393)=-1.79, p=$ 0.074) predicted perceived stress. Other significant predictors of perceived stress among AYC participants in the model were gender $(t(393)=-5.84, p<0.001)$ and the number of critical life events experienced $(t(393)=5.50, p<0.001)$. Hypothesis 5 was thus confirmed, and Hypothesis 6 was partly confirmed, supporting that recognition and support potentially mitigate role strain, and thereby promote mental health in adolescent young carers.

\section{Discussion}

The current study aimed to investigate mental health outcomes of adolescents' caring activities for close persons from a role perspective. Prior comparison studies between young carers and noncarers pointed to poorer mental health outcomes among carers. However, they typically used a decontextualized approach and, thereby, neglected the potential interplay of a caring role and the context in which caring occurs. By contrast, we assumed that the caring role has a unique impact on adolescents' experiences beyond the presence of a person with health problems and the further family context. Therefore, we compared levels of wellbeing and perceived stress between adolescents with a caring role and their noncarer peers who were either not confronted with a family member's health problems or did not have a substantial caring role. At the same time, we considered two indicators for an unstable family situation: economic hardship and disrupted family structure. Lastly, we evaluated associations of support and recognition for the caring role with mental health outcomes in carers.

The comparisons between the three groups showed that carers had significantly lower levels of well-being and higher levels of perceived stress compared with adolescents from the HF group. However, when comparing carers to the FHP group, there was no difference regarding well-being. Another important finding is that feeling recognized as a carer was associated with better well-being and perceived stress outcomes and feeling supported in caring with better well-being. Hence, the results support that poorer mental health outcomes among adolescents with a caring role can result from both the challenges of the caring role and the context in which caring occurs. Overall, these results favor a role perspective that ascribes role conflicts and overload as critical drivers to 
understand differences in perceived stress between young carers and noncarers. Moreover, support and recognition appear to be potential role facilitating factors.

Our finding that the AYC and the FHP groups showed similar levels of well-being could be explained in different ways. First, the act of caring itself may not affect emotional well-being in youth. However, the mere existence of an individual affected by health problems around them may explain their lower level of well-being. Previous studies highlighted the emotional impact of being confronted with a family member's health problems on adolescents (e.g., Pakenham \& Cox, 2014; de Roos et al., 2017). Moreover, many of the emotional difficulties described by adolescent young carers may be linked primarily to the circumstance of the health problem(s) per se (Ali et al., 2012; Stamatopoulos, 2018). For instance, young carers describe the amounts of worrying they do regarding the care recipient's well-being and health, or the anxiety related to a potential loss. Second, adjustment to adversity is multidimensional, suggesting that in some contexts, caring may help a person cope with the experience of the illness or disability of a person with whom they have a close emotional connection. From a theoretical perspective, acts of helping and caring in those situations can be both adaptive (e.g., shifting feelings of controllability) or adverse (i.e., exaggerated burden) for young people. Likewise, a few studies have shown that caring might be linked to positive and negative outcomes simultaneously (Ali et al., 2015; Barry, 2011; Joseph et al., 2009). Therefore, our findings may also support that caring is not exclusively related to negative experiences.

Supporting the role theory perspective suggesting that the caring role adds extra stress to the day-to-day life of adolescents, carers in this sample had consistently higher perceived stress scores than both noncarer groups (HF and FHP). This result thus confirms qualitative studies that demonstrated that being a young carer is linked to daily hassles and stressful experiences (e.g., Ali et al., 2012; McDougall et al., 2018) and two previous studies showing higher levels of stress among young carers compared to their noncarer peers (Charles, 2019; Hawken, 2019). This evidence indicates that altered levels of stress among adolescents growing up with a chronically ill family member (e.g., Sieh et al., 2013) are likely to be caused, at least to some extent, by youth's caring in these situations. This causal link is in line with the family ecology model (Pederson \& Revenson, 2005). The model proposes that parental health problems impact youth's stress experiences over family role redistributions (including changes in young people's roles and responsibilities) and was supported by previous research (e.g., Landi et al., 2021).

In our study sample, health problems in the family and unstable family circumstances were likely to exist simultaneously. Moreover, in the case of experienced economic hardship, youth were more likely to provide substantial care given when someone in the family had health problems. Thus, our results suggest that both characteristics-a caring role and having a history of an unstable economic family situation and/or a disrupted family composition-adversely impact well-being and perceived stress among adolescents. However, in contrast to our prediction, well-being and perceived stress between-group differences were attributable to being a carer and family instability in terms of additive effects, whereas no interaction effects were present.

In line with our assumption, perceived recognition of the caring role was a clear predictor of well-being and perceived stress among AYC participants. Only partly confirming our assumption, support for caring predicted wellbeing but not perceived stress. Our results are consistent with previous research showing that young carers wish to be recognized (Ali et al., 2012; van der Werf et al., 2020) and that support services specifically designed for young carers can positively impact their well-being (Ali et al., 2014). Our results further confirm Cassidy et al. (2014) who suggested that receiving positive feedback and acknowledgments for one's carer role is likely to facilitate a positive integration of the carer role into one's identity and enables positive experiences related to caring such as feeling competent and appreciated. This positive shift in turn is likely to increase well-being and to reduce perceived stress.

In contrast to our prediction, perceived support for the carers themselves did not predict lower levels of perceived stress among AYC participants. This finding could entail that perceived stress is not exclusively invoked by youth's caring tasks directly, but also essentially caused by conflicts between roles of multiple life domains (social, education, family, etc.; e.g., McDougall et al., 2018). Consequently, in stressful times, adolescents with a caring role primarily wish to be understood and heard by their teachers, instructors, friends, and family regarding their unique situation characterized by various demands.

Another aspect that might be worth discussing in this context is that young carers are sometimes hesitant to ask for help or accept help (Barry, 2011). Many of them learn how to cope and manage the caring situation by themselves. As experts of their situation, external support for the care recipient and themselves as carers sometimes seems to only make things more stressful and complicated in their eyes (van der Werf et al., 2020). However, support for their role as a carer had a substantial impact on AYC participants' well-being, which underpins the need for support structures tailored for this target group.

\section{Limitations and Areas for Future Studies}

The current study had several limitations. First, we relied on self-report data from the perspective of the young 
people themselves. Well-being is a subjective variable by definition, and according to stress and coping theory (Lazarus \& Folkman, 1984), subjective appraisals are likely to be a more vital determinant of adjustment than objective characteristics of a stressor. However, future research should include multiple perspectives on the caring situation and the impact of youth's caring (e.g., including care recipients' or teachers' perspectives). Second, a non-random sampling method was used that did not allow us to assess distinct reasons for non-responses at the individual level. Consequently, the generalizability of the results is limited due to potential selection bias. Last, our study used a cross-sectional design. To establish causal relationships between caring and other variables and to examine the long-term effects of caring on young people, longitudinal studies are needed.

Further research is also required to clarify further under what circumstances caring is beneficial for youth, including potential spill-over effects to other roles, and what characterizes a caring role that negatively impacts them. It is surprising that the caring context variables (e.g., the type of health problem or perceived caring responsibility) were hardly related to well-being and perceived stress. Our regression model explained about a fifth of the variance in both outcome variables, suggesting that many more variables could be involved. As an example, Saxena and Adamsons (2013) provide an overview of the range of potential factors on different levels that may be involved in youth's experiences in the context of a family member's health problems.

Regarding the individual level, future research should focus on variables such as personality and coping strategies. Our primary focus was on examining the caring role as a stressor for adolescents. Therefore, we chose to compare mental health outcomes between youth exposed to substantial and regular caring activities and those who were not. However, stress and coping theory indicates that the subjective way individuals appraise stressors is an important driver of stress responses and how they adjust emotionally (Lazarus \& Folkman, 1984).

On the family context level, future work should broaden the conceptualization of family instability. More specifically, it should also include qualitative aspects. In this study, we did not include youth's perceptions of the quality of family relationships. However, such an aspect of socioemotional (in)stability may likewise shape adolescent young carers' experiences of support and challenges both in families characterized by economic and structural stability or not. Moreover, information on the informal support system should be included since other studies have suggested that it is crucial whether young carers are the primary carer or rather in a helping role (e.g., Metzing et al., 2020).

Finally, variables from the macrosystem (laws, social policy, cultural practices, etc.) and exosystem (most importantly available health services) need to be considered as well.
This was the first study to examine potential moderator effects between a caring role and family instability for mental health outcomes and should be interpreted with caution. We hypothesize that the role of economic hardship and disrupted family composition in the context of young carers may differ considerably as a function of a country's health care system (e.g., regarding options for home care). Cross-national research is essentially needed to determine whether generalizations are appropriate.

\section{Practical Implications}

The findings of our study highlight the need to raise awareness about the topic of young carers among the general population, policymakers and professionals potentially working with young people and to design and develop appropriate interventions and support services. The results imply that those who are in contact with youth (e.g., at school, work, in healthcare, or in leisure clubs) should consider the possibility of family members with health problems (Sieh et al., 2013, de Roos et al., 2017) but also youth's potential caring roles. Perceived stress is an inner psychological state and is thus potentially invisible from the outside. Therefore, professionals must carefully pay attention to psychological reactions in adolescents who have a relative or close friend with health problems. Professionals should indicate their willingness to listen if youth wish to share their thoughts and feelings. Our results suggest that listening to young people with a caring role and making them feel understood is a suitable intervention for promoting their wellbeing and preventing daily stress. The study results further suggest that adolescent young carers can largely benefit from support services designed for youth growing up with an ill, disabled, or impaired family member (for examples, see Järkestig Berggren \& Hanson, 2016). Supporting and assisting youth in their caring responsibilities can further contribute to their well-being. Hence, intervention and service modules for young carers specifically should also be provided.

\section{Conclusion}

This study contributed significantly to an emerging body of research on the impact of caring on adolescents. First, the results suggest that being an adolescent young carer is a risk factor for increased stress levels. Second, having a family member with health problems is associated with lower levels of well-being in adolescents. Third, our data supported previous research indicating that substantial and regular caring activity by adolescents tends to coincide with a family history characterized by instability. 
Both aspects are associated with negative outcomes, thus highlighting adolescent young carers as a vulnerable group. Finally, the study also identified important predictors of adolescent young carers' resilience. Professionals should consider the role young people have in caring for their ill or disabled loved ones and how this level of caring may impact their own health and development. Making sure these young people are recognized and supported in their role-practically and emotionally-can make a substantial difference for them. Consequently, adolescent young carers feel supported, less lonely, and isolated with their situation, whereby a caring role's negative impact can be mitigated early on.

\section{Data availability}

Please note that the associated data have not been published in a depository yet. We aim to make the data available to other researchers via the Open Science Framework (https:// osf.io/sj3rp/) in 2021.

Author contributions Conceptualization, material preparation, data collection, analysis, and writing of the first draft were performed by $\mathrm{H}$. W., supervised by A.L. Both authors commented on previous versions of the manuscript, read and approved the final manuscript.

Funding Open Access funding provided by Universität Zürich. Part of this work was supported by Beisheim Stiftung, Ebnet-Stiftung, and Gesundheitsförderung Schweiz.

\section{Compliance with Ethical Standards}

Conflict of Interest The authors declare no competing interests.

Ethical Approval The questionnaire and methodology for this study was approved by the Institutional Human Research Review Board of the University of Zurich, Faculty of Arts and Social Sciences (No: 2018.2.6).

Informed Consent Informed consent and consent for publication of the anonymized data was obtained from all individual participants included in the study.

Publisher's note Springer Nature remains neutral with regard to jurisdictional claims in published maps and institutional affiliations.

Open Access This article is licensed under a Creative Commons Attribution 4.0 International License, which permits use, sharing, adaptation, distribution and reproduction in any medium or format, as long as you give appropriate credit to the original author(s) and the source, provide a link to the Creative Commons license, and indicate if changes were made. The images or other third party material in this article are included in the article's Creative Commons license, unless indicated otherwise in a credit line to the material. If material is not included in the article's Creative Commons license and your intended use is not permitted by statutory regulation or exceeds the permitted use, you will need to obtain permission directly from the copyright holder. To view a copy of this license, visit http://creativecommons. org/licenses/by/4.0/.

\section{References}

Ali, L., Ahlström, B. H., Krevers, B., \& Skärsäter, I. (2012). Daily life for young adults who care for a person with mental illness: A qualitative study. Journal of Psychiatric and Mental Health Nursing, 19(7), 610-617. https://doi.org/10.1111/j.1365-2850. 2011.01829.x

Ali, L., Krevers, B., Sjöström, N., \& Skärsäter, I. (2014). Effectiveness of web-based versus folder support interventions for young informal carers of persons with mental illness: A randomized controlled trial. Patient Education and Counseling, 94(3), 362-371. https://doi.org/10.1016/j.pec.2013.10.020

Ali, L., Krevers, B., \& Skärsäter, I. (2015). Caring situation, health, selfefficacy, and stress in young informal carers of family and friends with mental illness in Sweden. Issues in Mental Health Nursing, 36 (6), 407-415. https://doi.org/10.3109/01612840.2014.1002644

Barry, M. (2011). 'I realised that I wasn't alone': The views and experiences of young carers from a social capital perspective. Journal of Youth Studies, 14(5), 523-539. https://doi.org/10. $1080 / 13676261.2010 .551112$

Bastawrous, M. (2013). Caregiver burden-a critical discussion. International Journal of Nursing Studies, 50(3), 431-441. https:// doi.org/10.1016/j.ijnurstu.2012.10.005

Becker, F., \& Becker, S. (2008). Young adult carers in the UK. Princess Royal Trust for Carers

Becker, S. (2007). Global perspectives on children's unpaid caregiving in the family: research and policy on 'young carers' in the UK, Australia, the USA and Sub-Saharan Africa. Global Social Policy, 7(1), 23-50. https://doi.org/10.1177/1468018107073892

Becker, S., \& Sempik, J. (2019). Young adult carers: The impact of caring on health and education. Children \& Society, 33(4), 377-386. https://doi.org/10.1111/chso.12310

Brown, S. L. (2010). Marriage and child well-being: Research and policy perspectives. Journal of Marriage and Family, 72(5), 1059-1077. https://doi.org/10.1111/j.1741-3737.2010.00750.x

Cassidy, T., \& Giles, M. (2013). Further exploration of the Young Carers Perceived Stress Scale: Identifying a benefit-finding dimension. British Journal of Health Psychology, 18(3), 642-655. https://doi.org/10.1111/bjhp.12017

Cassidy, T., Giles, M., \& McLaughlin, M. (2014). Benefit finding and resilience in child caregivers. British Journal of Health Psychology, 19(3), 606-618. https://doi.org/10.1111/bjhp.12059

Charles, G. (2019). General profile, social and health comparisons of high school age young carers to their non-caregiving peers. Relational Child and Youth Care Practice, 32(1), 7-21

Cipolletta, S., Morrison, V., \& Vilchinsky, N. (2020). Editorial: Caregiving and social support in the context of health and illness. Frontiers in Psychology, 11, 620357. https://doi.org/10.3389/ fpsyg.2020.620357

Cohen, S., Kamarck, T., \& Mermelstein, R. (1983). A global measure of perceived stress. Journal of Health and Social Behavior, 24(4), 385-396

Conger, R. D., Conger, K. J., \& Martin, M. J. (2010). Socioeconomic status, family processes, and individual development. Journal of Marriage and Family, 72(3), 685-704. https://doi.org/10.1111/j. 1741-3737.2010.00725.x

Crosnoe, R., \& Cavanagh, S. E. (2010). Families with children and adolescents: A review, critique, and future agenda. Journal of Marriage and Family, 72(3), 594-611. https://doi.org/10.1111/j. 1741-3737.2010.00720.x

Dharampal, R., \& Ani, C. (2020). The emotional and mental health needs of young carers: What psychiatry can do. BJPsych Bulletin, 44(3), 112-120. https://doi.org/10.1192/bjb.2019.78

Frech, M., Berger, F., Rabhi-Sidler, S., Nagl-Cupal, M., Becker, S., \& Leu, A. (2021). How professional support for young carers 
benefits from a salutogenic approach. International Journal of Care and Caring, Advance online publication. https://doi.org/ 10.1332/239788221X16196023939801

Frech, M., Nagl-Cupal, M., Leu, A., Schulze, G. C., Spittel, A. -M., \& Kaiser, S. (2019). Wer sind Young Carers? Analyse der Begriffsverwendung im deutschsprachigen Raum und Entwicklung einer Definition [Who are "Young Carers"? Analysis of the use of the term in German speaking countries and development of a definition]. International Journal of Health Professions, 6(1), 19-31. https://doi.org/10.2478/ijhp-2019-0004

Greene, J., Cohen, D., Siskowski, C., \& Toyinbo, P. (2017). The relationship between family caregiving and the mental health of emerging young adult caregivers. The Journal of Behavioral Health Services \& Research, 44(4), 551-563. https://doi.org/10. 1007/s11414-016-9526-7

Haugland, B. S. M., Hysing, M., \& Sivertsen, B. (2019). The burden of care: A national survey on the prevalence, demographic characteristics and health problems among young adult carers attending higher education in Norway. Frontiers in Psychology, 10, 2859 https://doi.org/10.3389/fpsyg.2019.02859

Hawken, T. (2019). The experiences of Young Carers: Towards an understanding of stress and the development of psychophysiological resilience [Doctoral Thesis]. University of Bath. https:// researchportal.bath.ac.uk/en/studentTheses/the-experiences-ofyoung-carers-towards-an-understanding-of-stres

Hindin, M. J. (2007). Role Theory. In G. Ritzer (Ed.), The Blackwell encyclopedia of sociology. Blackwell. https://doi.org/10.1002/ 9781405165518.wbeosr078

Järkestig Berggren, U., \& Hanson, E. (2016). Children as next of kin: A scoping review of support interventions for children who have a parent with a serious physical illness. Child Care in Practice, 22(3), 277-295. https://doi.org/10.1080/13575279.2015.1102125

Johnson, M. K., Crosnoe, R., \& Elder, G. H. (2011). Insights on adolescence from a life course perspective. Journal of Research on Adolescence, 21(1), 273-280. https://doi.org/10.1111/j.15327795.2010.00728.x

Joseph, S., Becker, S., Becker, F., \& Regel, S. (2009). Assessment of caring and its effects in young people: Development of the Multidimensional Assessment of Caring Activities Checklist (MACA-YC18) and the Positive and Negative Outcomes of Caring Questionnaire (PANOC-YC20) for young carers. Child: Care, Health and Development, 35(4), 510-520. https://doi.org/ 10.1111/j.1365-2214.2009.00959.x

Joseph, S., Becker, S., Elwick, H., \& Silburn, R. (2012). Adult carers quality of life questionnaire (AC-QoL): Development of an evidence-based tool. Mental Health Review Journal, 17(2), 57-69. https://doi.org/10.1108/13619321211270380

Joseph, S., Kendall, C., Toher, D., Sempik, J., Holland, J., \& Becker, S. (2019). Young carers in England: Findings from the 2018 BBC survey on the prevalence and nature of caring among young people. Child: Care, Health and Development, 45(4), 606-612. https://doi.org/10.1111/cch.12674

Klein, E. M., Brähler, E., Dreier, M., Reinecke, L., Müller, K. W., Schmutzer, G., Wölfling, K., \& Beutel, M. E. (2016). The German version of the Perceived Stress Scale-psychometric characteristics in a representative German community sample. BMC Psychiatry, 16, 159. https://doi.org/10.1186/s12888-016-0875-9

Lakman, Y., \& Chalmers, H. (2019). Psychosocial comparison of carers and noncarers. Child \& Youth Services, 40(2), 200-219. https://doi.org/10.1080/0145935X.2018.1553614

Landi, G., Pakenham, K. I., Benassi, M., Giovagnoli, S., Tossani, E., \& Grandi, S. (2021). A model of the effects of parental illness on youth adjustment and family functioning: The moderating effects of psychological flexibility on youth caregiving and stress. International Journal of Environmental Research and Public Health, 18(9). https://doi.org/10.3390/ijerph18094902
Lang, G., \& Bachinger, A. (2017). Validation of the German Warwick-Edinburgh Mental Well-Being Scale (WEMWBS) in a community-based sample of adults in Austria: A bi-factor modelling approach. Journal of Public Health, 25(2), 135-146. https://doi.org/10.1007/s10389-016-0778-8

Lazarus, R. S., \& Folkman, S. (1984). Stress, appraisal, and coping. Springer

Leu, A., \& Becker, S. (2019). Young Carers. In H. Montgomery (Ed.), Oxford bibliographies in childhood studies. Oxford University Press. https://doi.org/10.1093/OBO/9780199791231-0120

Leu, A., Frech, M., \& Jung, C. (2018). Young carers and young adult carers in Switzerland: Caring roles, ways into care and the meaning of communication. Health \& Social Care in the Community, 26(6), 925-934. https://doi.org/10.1111/hsc.12622

Leu, A., Frech, M., Wepf, H., Sempik, J., Joseph, S., Helbling, L., Moser, U., Becker, S., \& Jung, C. (2019). Counting young carers in Switzerland-A study of prevalence. Children \& Society, 33 (1), 53-67. https://doi.org/10.1111/chso.12296

Leu, A., Wepf, H., Sempik, J., Nagl-Cupal, M., Becker, S., Jung, C., \& Frech, M. (2020). Caring in mind? Professionals' awareness of young carers and young adult carers in Switzerland. Health \& Social Care in the Community, 28(6), 2390-2398. https://doi.org/ 10.1111/hsc. 13061

Levine, C., Hunt, G. G., Halper, D., Hart, A. Y., Lautz, J., \& Gould, D. A. (2005). Young adult caregivers: A first look at an unstudied population. American Journal of Public Health, 95(11), 2071-2075. https://doi.org/10.2105/AJPH.2005.067702

Low, N. C., Dugas, E., O'Loughlin, E., Rodriguez, D., Contreras, G., Chaiton, M., \& O'Loughlin, J. (2012). Common stressful life events and difficulties are associated with mental health symptoms and substance use in young adolescents. BMC Psychiatry, 12, $116 \mathrm{https} / / /$ doi.org/10.1186/1471-244X-12-116

McDougall, E., O’Connor, M., \& Howell, J. (2018). "Something that happens at home and stays at home": An exploration of the lived experience of young carers in Western Australia. Health \& Social Care in the Community, 26(4), 572-580. https://doi.org/10.1111/ hsc. 12547

Metzing, S., Ostermann, T., Robens, S., \& Galatsch, M. (2020). The prevalence of young carers-a standardised survey amongst school students (KiFam-study). Scandinavian Journal of Caring Sciences, 34(2), 501-513. https://doi.org/10.1111/scs.12754

Nap, H. H., Hoefman, R., Jong, N., de, Lovink, L., Glimmerveen, L., Lewis, F., Santini, S., D’Amen, B., Socci, M., Boccaletti, L., Casu, G., Manattini, A., Brolin, R., Sirk, K., Hlebec, V., Rakar, T., Hudobivnik, T., Leu, A., Berger, F., \& Hanson, E. (2020). The awareness, visibility and support for young carers across Europe: A Delphi study. BMC Health Services Research, 20(1), 921 https://doi.org/10.1186/s12913-020-05780-8

Neuenschwander, M. P. (1998). Schule und Identität im Jugendalter I. Kurzdokumentation der Skalen und Stichproben. Forschungsbericht Nr. 18 [School and Identity in Youth I. Brief methodological report]. Bern.

Nickels, M., Siskowski, C. T., Lebron, C. N., \& Belkowitz, J. (2018). Medication administration by caregiving youth: An inside look at how adolescents manage medications for family members. Journal of Adolescence, 69, 33-43. https://doi.org/10.1016/j. adolescence.2018.09.001

Pakenham, K. I., Bursnall, S., Chiu, J., Cannon, T., \& Okochi, M. (2006). The psychosocial impact of caregiving on young people who have a parent with an illness or disability: Comparisons between young caregivers and noncaregivers. Rehabilitation Psychology, 51(2), 113-126. https://doi.org/10.1037/0090-5550. 51.2.113

Pakenham, K. I., \& Cox, S. D. (2014). The effects of parental illness and other ill family members on the adjustment of children. Annals of Behavioral Medicine: A Publication of the Society of 
Behavioral Medicine, 48(3), 424-437. https://doi.org/10.1007/ s12160-014-9622-y

Pakenham, K. I., \& Cox, S. (2015). The effects of parental illness and other ill family members on youth caregiving experiences. Psychology \& Health, 30(7), 857-878. https://doi.org/10.1080/ 08870446.2014.1001390

Pederson, S., \& Revenson, T. A. (2005). Parental illness, family functioning, and adolescent well-being: A family ecology framework to guide research. Journal of Family Psychology, 19(3), 404-419. https://doi.org/10.1037/0893-3200.19.3.404

Perrig-Chiello, P., Höpflinger, F., \& Schnegg, B. (2010). Pflegende Angehörige von älteren Menschen in der Schweiz [Family carers of elderly in Switzerland. Final report.]: Swiss Age Care-2010 Forschungsprojekt im Auftrag von Spitex-Schweiz. Schlussbericht. https://www.spitex.ch/files/CEAAGB6/SwissAgeCare-2010--Schlussbericht

Robison, O. M. E. F., Inglis, G., \& Egan, J. (2020). The health, wellbeing and future opportunities of young carers: A population approach. Public Health, 185, 139-143. https://doi.org/10.1016/j. puhe.2020.05.002

de Roos, S. A., de Boer, A. H., \& Bot, S. M. (2017). Well-being and need for support of adolescents with a chronically ill family member. Journal of Child and Family Studies, 26(2), 405-415. https://doi.org/10.1007/s10826-016-0574-7

Santini, S., Socci, M., D’Amen, B., Di Rosa, M., Casu, G., Hlebec, V., Lewis, F., Leu, A., Hoefman, R., Brolin, R., Magnusson, L., \& Hanson, E. (2020). Positive and negative impacts of caring among adolescents caring for grandparents. Results from an online survey in six European countries and implications for future research, policy and practice. International Journal of Environmental Research and Public Health, 17(18). https://doi. org/10.3390/ijerph17186593

Saxena, M., \& Adamsons, K. (2013). Siblings of individuals with disabilities: Reframing the literature through a bioecological lens. Journal of Family Theory \& Review, 5(4), 300-316. https://doi. org/10.1111/jftr.12021

Shifren, K. (Ed.) (2009). How caregiving affects development: Psychological implications for child, adolescent, and adult caregivers. American Psychological Association. https://doi.org/10. 1037/11849-000.

Sieh, D. S., Visser-Meily, J. M. A., \& Meijer, A. M. (2013). Differential outcomes of adolescents with chronically ill and healthy parents. Journal of Child and Family Studies, 22(2), 209-218. https://doi.org/10.1007/s10826-012-9570-8

Siskowski, C. T. (2009). Adolescent caregivers. In K. Shifren (Ed.), How caregiving affects development: Psychological implications for child, adolescent, and adult caregivers. American Psychological Association

Smyth, C., Blaxland, M., \& Cass, B. (2011). 'So that's how I found out I was a young carer and that I actually had been a carer most of my life'. Identifying and supporting hidden young carers. Journal of Youth Studies, 14(2), 145-160. https://doi.org/10. 1080/13676261.2010.506524

Stamatopoulos, V. (2015). One million and counting: The hidden army of young carers in Canada. Journal of Youth Studies, 18(6), 809-822. https://doi.org/10.1080/13676261.2014.992329

Stamatopoulos, V. (2018). The young carer penalty: Exploring the costs of caregiving among a sample of Canadian youth. Child \& Youth Services, 39(2-3), 180-205. https://doi.org/10.1080/ 0145935X.2018.1491303

Tennant, R., Hiller, L., Fishwick, R., Platt, S., Joseph, S., Weich, S., Parkinson, J., Secker, J., \& Stewart-Brown, S. (2007). The Warwick-Edinburgh Mental Well-being Scale (WEMWBS): Development and UK validation. Health and Quality of Life Outcomes, 5, 63. https://doi.org/10.1186/1477-7525-5-63.

Tomasetti, D. C. (2016). Ecological Approach. In C. L. Shehan \& M. Duncan (Eds.), Wiley Blackwell encyclopedias in social science. The Wiley Blackwell encyclopedia of family studies (pp. 1-6). Wiley Blackwell. https://doi.org/10.1002/9781119085621.wbefs214

Tseliou, F., Rosato, M., Maguire, A., Wright, D., \& O'Reilly, D. (2018). Variation of caregiver health and mortality risks by age: A censusbased record linkage study. American Journal of Epidemiology, 187 (7), 1401-1410. https://doi.org/10.1093/aje/kwx384

van der Werf, H. M., Paans, W., Emmens, G., Francke, A. L., Roodbol, P. F., \& Luttik, M. L. A. (2020). Expectations and prospects of young adult caregivers regarding the support of professionals: A qualitative focus group study. International Journal of Environmental Research and Public Health, 17(12). https://doi.org/10.3390/ijerph17124299

Wepf, H., Kaspar, H., Otto, U., Bischofberger, I., \& Leu, A. (2017). Betreuende und pflegende Angehörige-Präzisierung und Öffnung eines schwierigen Begriffs: [Family carers-clarification and opening up of a complex concept]. Pflegerecht, 6(3), $140-146$ 